\title{
Correction: Persoons, T.; Cressall, R.; Alimohammadi, S. Validating a Reduced-Order Model for Synthetic Jet Actuators Using CFD and Experimental Data. Actuators 2018, 7, 67
}

\author{
Tim Persoons ${ }^{1, *(\mathbb{D})}$, Rick Cressall ${ }^{1,2}$ and Sajad Alimohammadi ${ }^{1,3} \mathbb{D}$ \\ 1 School of Engineering, Parsons Building, Trinity College, Dublin 2, Ireland; rcressal@tcd.ie or \\ rcressal@nd.edu (R.C.); alimohas@tcd.ie or sajad.alimohammadi@dit.ie (S.A.) \\ 2 Department of Aerospace and Mechanical Engineering, University of Notre Dame, \\ South Bend, IN 46556, USA \\ 3 Mechanical \& Design Engineering School, Dublin Institute of Technology, Dublin 2, Ireland \\ * Correspondence: tim.persoons@tcd.ie; Tel.: +353-1-896-1936
}

Received: 14 February 2019; Accepted: 14 February 2019; Published: 19 February 2019

check for updates

The authors wish to make the following corrections to this paper [1] in Section 2.2, Equation (19). The authors wish to replace:

Alternatively, the following equation is an empirical fit for $\beta$ that is valid for $1<a<50$ and $k A_{n}^{1 / 2}<0.886$ with a mean error of $1.7 \%$ and a maximum error of $5.9 \%$ :

$$
\begin{gathered}
\beta \approx-0.34064+6.6771 \times 10^{-2} k A_{n}^{1 / 2}+1.5318 \times 10^{-4} a^{2}+2.7233 \times 10^{-8} a^{4}+ \\
0.78343 \exp \left(-1.7384 \times 10^{-2} a\right)
\end{gathered}
$$

While Equation (19) is only valid for aspect ratios not exceeding 50, the value of $\beta$ from Equations (16)-(18) in the limit for infinite aspect ratio $(a \rightarrow \infty)$ is zero.

with:

Alternatively, the following equation is an empirical fit for $\beta$ that is valid for any aspect ratio $a \geq 1$ and $k A_{n}^{1 / 2}<0.886$, with a mean error of $1.9 \%$ and a maximum error of $7.9 \%$ for $1<a<50$ :

$$
\beta \approx 0.5316 \exp \left(-0.181 a^{0.44}\right)-0.05247 k A_{n}^{1 / 2}
$$

In the limit for infinite aspect ratio $(a \rightarrow \infty)$, the low-frequency approximation of $\beta$ obtained from Equations (16)-(19) is zero.

The authors would like to apologize for any inconvenience caused to the readers by these changes.

\section{Reference}

1. Persoons, T.; Cressall, R.; Alimohammadi, S. Validating a Reduced-Order Model for Synthetic Jet Actuators Using CFD and Experimental Data. Actuators 2018, 7, 67. [CrossRef]

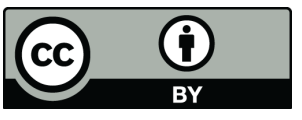

(C) 2019 by the authors. Licensee MDPI, Basel, Switzerland. This article is an open access article distributed under the terms and conditions of the Creative Commons Attribution (CC BY) license (http://creativecommons.org/licenses/by/4.0/). 